Al-Manhaj: Journal of Indonesian Islamic Family Law, 1 (2), 2019: 114-123

ISSN: 2715-003; E-ISSN 2714-5514

DOI: http://dx.doi.org/10.19105/al-manhaj.v1i2.3138

\title{
Nikah Sirri Perspektif Maqashid Syariah
}

\author{
Muhamad Taufiq \\ (International Islamic University Malaysia, Jalan Gombak, 53100, \\ Selangor, Malaysia)
}

\begin{abstract}
Abstrak:
Nikah sirri menimbulkan pro kontra di berbagai lapisan masyarakat, dari ulama, praktisi hukum hingga tokoh masyarakat. Perbedaan pendapat ini karena perbedaan persepsi. Ulama melihat dari sisi legalitas Syariah, praktisi hukum berpedoman pada Kompilasi Hukum Islam, sedangkan tokoh masyarakat lebih melihat kepada tatanan sosial. Paper ini mencoba mengkaji hukum Nikah Sirri perspektif Maqashid Syariah dengan mempertimbangkan antara maslahat dan mafsadat dalam kajian filsafat hukum Islam. (The reality of "Sirri marriages" has raised pros and cons in various circles: from the 'ulama, legal practitioners to community leaders. This difference of opinion is due to differences in perception. The 'Ulama consider the legality in Shari'ah terms, legal practitioners are guided by the Compilation of Islamic Law, while community leaders look more at social order. This paper examines Sirri's marriage law from the perspective of Maqashid Sharia by considering between maslahat and mafsadat in the study of Islamic legal philosophy.)
\end{abstract}

\section{Kata Kunci:}

Nikah Sirri;Maqashid Syariah;Maslahat;Mafsadat

\section{Pendahuluan}

Islam diturunkan oleh Allah swt. melalui Rasulullah saw. Untuk menegakkan masalahat. Dalam hal ini, Islam merupakan agama"rahmatan lil-'alamin", artinya bahwa kedatangannya adalah

Available online at:

http://ejournal.iainmadura.ac.id/index.php/almanhaj/index

email koresproden: mh.taufiq.phd@gmail.com

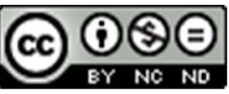


sebagai berkah dan karunia bagi seluruh umat manusia. Sehingga, secara ideal, titik tolak sekaligus tujuan Islam adalah kebaikan bukan saja bagi kaum Muslim secara khusus, tetapi seluruh umat manusia. Sehingga, dalam filsafat hukum Islam dikenal terminologi "maqashid al-syari'ah", atau tujuan/maksud ditetapkannya syariat.

Pernikahan disyariatkan dalam Islam untuk kemaslahan manusia. Dilihat dari nilai maqashid syariah-nya, pernikahan disyariatkan karena untuk hifdzu al-nasl yang berarti menjaga keturunan. Pernikahan dalam Islam sangat sakral sekali. Bahkan Rasulullah saw. menganjurkan kepada para pemuda agar segara menikah.

Pembicaraan mengenai nikah sirri akhir-akhir ini menjadi menarik dan masih hangat dibicarakan. Mengingat masih banyaknya masyarakat melakukan nikah sirri dengan beragam alasan, bukan hanya masyarakat biasa yang melakukan, bahkan pejabat negara sekalipun masih banyak melakukan nikah sirri.

Tidak hanya di Indonesia, nikah sirri juga marak dilakukan di negara-negara berpenduduk muslim lainnya. Sebut saja, Arab Saudi, Mesir, Yaman, Syiria dan lainnya. Oleh karena itu, penulis berusah membahas "Legalitas Nikah Sirri ditinjau dari Maqashid Syariah".

\section{Definisi Nikah Sirri}

Sebelum mengetahui definisi nikah sirri, penulis akan menjabarkan definisi nikah terlebih dahulu. Nikah menurut bahasa adalah menggabungkan. Kemudia berdasarkan versi bahasa ini, ahli bahasa berbeda pendapat, ada yang mengartikan bahwa hakikat nikah adalah jima'. Dan ada ulama yang menyatakan bahwa hakikat nikah adalah akad. ${ }^{1}$

Sedangkan nikah dalam istilah fikih adalah akad yang berfungsi agar halalnya melakukan jima' dengan lafad nikah atau kawin atau terjemahannya. ${ }^{2}$

\footnotetext{
${ }^{1}$ Ahmad Al-Hamwy, Al-Mishbah al-Munir, (Beirut, al-Maktabah al-Ilmiyah, $\mathrm{tc}, \mathrm{tt})$, Juz 2, 756.

2 Ahmad ibn Umar al-Syathiri al-Yamany, Yaqut al-Nafis, (Demasyqus, Muassasah al-Risalah Nasherun, cet. I, tt.), 141.
} 
Kata sirri berasal dari bahasa Arab, yang bermakna rahasia. Jadi nikah sirri menurut bahasa berarti pernikahan rahasia. ${ }^{3}$ Dalam mendefinisikan nikah sirri, ulama berpeda pendapat.

Menurut mayaritas Ulama dari kalangan Hanafiah, Syafiah dan Hanabilah, mendefinisikan bahwa nikah sirri adalah pernikahan yang tidak dihadiri dua saksi. Sehingga Pernikahan yang disaksikan dua saksi menurut mereka adalah pernikahan 'alaniyah (bukan pernikahan sirri). ${ }^{4}$

Mereka berlandaskan sabda Rasulullah Saw.

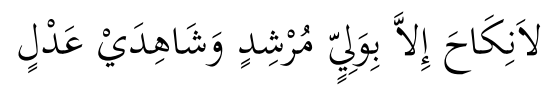

“Tidak sah sebuah pernikahan kecuali ada wali dan dua saksi yang adil." 5

Dari hadis ini, para Ulama dari kalangan Hanafiah, Syafiah dan Hanabilah bahwa pernikahan tetap sah meskipun tidak diumumkan ke halayak umum, karena pernikahan merupakan akad antara wali dan saksi sehingga tidak disyaratkan pengumuman, seperti halnya akad transaksi jual beli.

Sedangkan hadist Rasulullah yang berbunyi

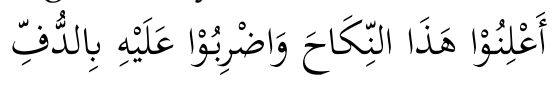

“Umumkanlah pernikahan ini dan ramaikanlah dengan rebana" 6

Hadis ini menunjukkan kesunnahan, karena perintah untuk meramaikan dengan rebana dan suara bukanlah sebuah kewajiban.

${ }^{3}$ Kamus Al-Munawwir aplikasi offline.

${ }^{4}$ Alauddin al-Kasany, Badai' Shona-i', (Beirut: Dar al-Kutub al-Ilmiyah, cet. 2, 1986 M/1406 H) Juz 2, 253. Muhammad al-Mawardi, al-Hawi al-Kabir, (Beirut: Dar al-Kutub al-Ilmiyah, cet. 1, 1999 M/ 1419 H), juz 11, 86. Ibnu Qudamah, al-Mughni, (Kairo: Maktaba al-Qahirah, tc. 1968 M/1388 H), juz 6, 538.

${ }^{5}$ Hadist ini diriwayatkan al-Bayhaqi, al-Sunan al-Kubra (India, Dairah alMa'arif al-Ustmaniyah, cet. 1, $1344 \mathrm{H}$ ), Juz 7, 125. Menurut al- Manawi berdasarkan pernyataan al-Dzahabi bahwa sanad hadits ini shahih, lihat! AlManawi, Faidhu al-Qadir, (Mesir: al-Maktabah al-Tijariyah al-Kubra, cet. 1, $1356 \mathrm{H})$ juz 6, 486.

${ }^{6}$ Hadits ini diriwayatkan oleh Imam al-Tirmidzi, Sunan al-Tirmidy, (Mesi: alHalby, cet. II, 1975 M/ 1395 M), juz 3, 389-390. 
Atau perintah di atas merupakan kewajiban untuk mengumumkan pernikahana dengan dua saksi.

Sedangkan sabda Rasulullah yang menyatakan haramnya nikah sirri, adalah pernikahan yang tidak disaksikan dua saksi. Hal ini berlandaskan:

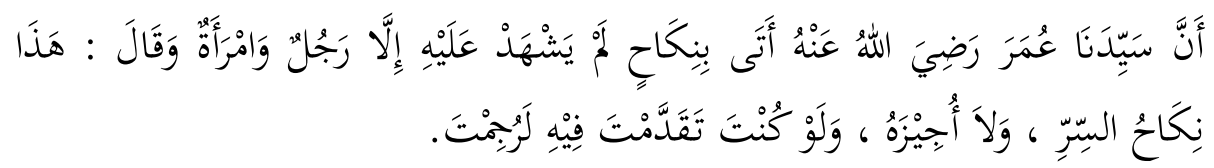

"Bahwa Sayyidina Umar Ra mendatangi sebuah pernikahan yang hanya dihadiri oleh saksi laki-laki dan perempuan, dan Sayyidina Umar berkata "Ini adalah nikah sirri, dan saya menyatakan hal itu tidak boleh, jika sampai terjadi maka dirajam". ${ }^{7}$

Dalam menyikapi nikah sirri, madzhab Ulama Malikiah, terbagi dua pendapat:

Pertama; menurut al-Baji, nikah sirri adalah pernikahan yang dirahasiakan kepada halayak umum kecuali kepada dua saksi.

Kedua; menurut Ibnu Rif'ah, nikah sirri adalah pernikahan yang diwasiatkan baik kepada saksi ataupun selain saksi, agar pernikahan tersebut dirahasiakan. Dan yang berwasiat untuk merahasiakan adalah suami. 8

\section{Potret Nikah Sirri di Indonesia dan Timur Tengah}

Setelah kita mengetahui definisi nikah sirri dari literatur fikih klasik, dari berbagai madzhab, maka selanjutnya penulis memberikan gambaran potret pernikahan sirri yang terjadi di Indonesia dan Timur Tengah. Apakah praktik nikah sirri di Indonesia dan Timur Tengah

7 Hal ini merupakan atsar Sayyidina Umar, yang diriwayatkan oleh Imam Malik dalam al-Muwaththa', (Demasyqus, Dar al-Qalam, cet. I, 1991 M/ 1413 H), juz 2, 535.

8 Syamsuddin al-Ru'ayni, Mawahibu al-Jalil, (Beirut: Dar al-Fikr, cet. III, 1992 M/ 1412 H) juz 3, 409-410, Malik al-Madani, al-Mudawwanah, (Beirut: Dar alKutub al-Ilmiyah, 1994 M/ 1415 H), juz 2, 194 (Beirut, Dar Shadir), Muhammad al-Dasuqi, hasiyah al-Dasuqi, (Beirut: Dar al-Fikr, tc, tt,) juz 2, 236-237. 
keduanya sama ataukah berbeda? Dalam hal ini, penulis memberikan potret nikah sirri di Indonesia terlebih dahulu, lalu potret nikah sirri di Timur Tengah.

Sejauh pengamatan penulis, nikah sirri di Indonesia dipraktikkan sesuai dengan syarat dan ketentuan dalam pernikahan Islam, hanya saja tidak ada pencatatan buku nikah. Nikah sirri marak dilakukan dari kalangan rakyat biasa, hingga pejabat tinggi negara.

Terkadang nikah sirri juga dipraktikkan oleh kalangan pelajar/mahasiswa. Karena bagi mereka, pernikahan dini lebih baik dari pada terjerumus ke lembah pergaulan bebas. Biasanya, sang pria sudah lulus sekolah sedangkan sang wanita masih duduk di bangku sekolah. Sehingga mereka melangsungkan pernikahan sirri. Nikah sirri semacam ini sesuai dengan syarat dan ketentuan syariat Islam, bahkan sampai mengundang tetangga untuk resepsi pernikahan, hanya saja tidak dicatat dalam KUA karena sang mempelai wanita masih duduk di bangku sekolah.

Beda halnya nikah sirri di Arab saudi dan Negara Timur Tengah lainnya. Nikah sirri di negara minyak tersebut sangatlah rahasia. Bahkan terkadang hanya diketahui oleh orang-orang tertentu; biasanya wali dan dua saksi.

Nikah sirri di Timur Tengah menjadi sebuah solusi karena banyaknya perawan tua yang tidak menikah. Para pria lajangpun takut, karena jumlah mahar yang mahal menggunung. Sehingga mereka melangsungkan nikah sirri demi menyalurkan kebutuhan biologisnya.

\section{Nikah Sirri ditinjau dari Maqashid Syariah}

Setelah kita mengetahui definisi dan potret Nikah sirri di Indonesia dan Timur Tengah, maka penulis membahas legalitas nikah sirri ditinjau dari maqashid syariah Maqashid syariat merupakan tujuantujuan yang diletakkan oleh syariat Islam untuk mewujudkan untuk kemaslahatan bagi individu dan masyarakat luas. ${ }^{9}$

Inti dari maqashid syariat Islam adalah mewujudkan kemaslahatan dan mencegah mafsadah. Imam al-Ghazali

${ }_{9}$ Ibnu Asyur, Maqashid al-Syariah al-Islamiyah, (Yordania; Dar al-Nafais, cet. II, $1421 \mathrm{H} / 2001 \mathrm{M}), 71$. 
mendifinisikan maslahat dengan menjaga tujuan syariat Islam yang terangkum dalam lima prinsip dasar (baca, Kulliyatu al-Khamsah). ${ }^{10}$ Kulliyatu al-Khamasah yaitu hifdzu al-Dien, hifdzu al-Nafs. hifdzu alNasl, hifdzu al-Mal, dan hifdzu al-Aql.

Dalam maqashid syariat Islam terdapat kaidah kulliyah. Kaidah kulliyah ini meliputi al-dharuriyat (primer), al-hajiyat (sekunder) dan altahsiniyat (tersier). ${ }^{11}$

Al-Dharuriyat secara bahasa merupakan kata plural dari dharury yang berarti sesuatu yang sangat dibutuhkan mencapai tingkat darurat. Meliputi; menegakkan agama (hifdz al-dien), perlindungan jiwa (hifdz al-nafs), proteksi akal (hifdz al-'aql), pemeliharaan keturunan (hifdz al-nasl), perlindungan harta (hifdz almal).

Al-Hajiyat adalah sesuatu yang dibutuhkan, namun tidak sampai pada tingkat darurat. Misalnya transaksi jual beli, transaksi sewa dan sebagainya. Tahsiniyat adalah sesuatu yang dianggap baik secara adat tanpa ada kebutuhan yang mendasar. Seperti menghilakan keahlian syahadat bagi budak.12

Dalam kasus nikah sirri yang tidak disaksikan dua saksi, ulama klasik berbeda pendapat:

Menurut pendapat mayoritas ulama dari kalangan madzhab Hanafiah, Syafiiyah dan Hanabilah, bahwa nikah sirri menurut mereka adalah pernikahannya tidak sah, karena tidak ada persaksian dari dua saksi yang adil. ${ }^{13}$

Mereka berlandaskan hadist Rasulullah saw:

$$
\text { لاَنِكَاحَ إلاَّ بَوَلِيّ وَشَاهِدَيْ عَدْلِ }
$$

10 Al-Ghazaly, al-Mustashfa, (Beirut: Dar al-Kutub al-Ilmiyah, cet. 1, 1993 M/ $1413 \mathrm{H}), 174$.

11 Al-Syatiby, al-Muwafaqat, (Dar Ibnu Affan, cer. 1, 1997 M/1417 M), Juz 3 117.

12 Al-Mahally, Syarh al-Jalal Mahally 'ala Jam'i al-Jawami', (Dar al-Kutub alIlmiyah, tt, tc.), Juz 2, hlm. 322-324.

${ }_{13}$ Alauddin al-Kasany, Badai' Shona-i', (Beirut: Dar al-Kutub al-Ilmiyah, cet. 2, 1986 M/1406 H), juz 2, 253, Muhammad al-Mawardi, al-Hawi al-Kabir, (Beirut: Dar al-Kutub al-Ilmiyah, cet. 1, 1999 M/ 1419 H), juz 11, hal 84-86, Ibnu Qudamah, al-Mughni, (Kairo: Maktaba al-Qahirah, tc. 1968 M/1388 H), juz 6, 538 . 
“Tidak sah sebuah pernikahan kecuali ada wali dan dua saksi yang adil." 14

Sedangkan nikah sirri menurut pendapat ulama Malikiyah, maka ada dua pendapat. Pertama, pernikahannya sah, tapi harus difasakh sebelum melakukan hubungan jima' atau sudah melakukan hubungan intim tapi belum terlalu lama. Jika sudah berhubungan intim dengan waktu yang lama maka tidak di-faskh menurut pendapat yang Mashur, beda halnya Syekh Ibnu Haji berpendapat lain yaitu tetap di-faskh meskipun sudah berhubungan intim terlalu lama. Sedangkan kategori 'lama' dalam berhubungan intim kembali pada adat istiadat.

Dan fashk dalam permasalahan ini dengan talak. Karena berdasarkan pernikahan siri yang masuk dalam permasalahan yang diperdebatkan antar ulama. Dan pasangan suami istri yang nikah sirri dihukum jika sampai melakukan hubungan intim. Namun jika suamiistri ada udzur (karena tidak mengetahui atau karena majbur diperintahkan- oleh orang tuanya) maka tidak dihukum. ${ }^{15}$

Menurut penulis, pendapat mayoritas ulama lebih unggul dalam hal ini. Karena pernikahan tidak sah jika tidak memenuhi syarat dan rukun dalam pernikahan, sedangkan nikah sirri yang tidak disaksikan dua saksi tidak memenuhi syarat dan ketentuan. Dan syarat dan ketentuan tersebut memiliki nilai-nilai maqashid syariah Islam. Dan nilai maqashid syariah dalam persyaratan dua saksi yaitu kembali pada hifdzu al-dzin dan hifdzu al-nasl.

Sedangkan nikah sirri yang disaksikan oleh dua saksi yang keduanya disuruh merahasiakan, maka ulama juga terjadi perbedaan pendapat:

14 Hadist ini diriwayatkan al-Bayhaqi, al-Sunan al-Kubra (India, Dairah alMa'arif al-Ustmaniyah, cet. 1, $1344 \mathrm{H})$, Juz 7, 125. Menurut al- Manawi berdasarkan pernyataan al-Dzahabi bahwa sanad hadits ini shahih, lihat! AlManawi, Faidhu al-Qadir, (Mesir: al-Maktabah al-Tijariyah al-Kubra, cet. 1, 1356 H) juz 6, 486.

15 Malik al-Madani, al-Mudawwanah, (Beirut: Dar al-Kutub al-Ilmiyah, 1994 M/ 1415 H), juz 2, hal 194, Muhammad al-Dasuqi, hasiyah al-Dasuqi, (Beirut: Dar al-Fikr, tc, tt,), juz 2, 236-237. 
Menurut pendapat ulama Hanafiah, Syafiiyah, dan sebagian ulama Malikiyah, pernikahan sirri yang disaksikan dua saksi yang keduanya disuruh merahasiakannya, maka hukumnya sah. ${ }^{16}$

Sedangkan Ulama Hanabilah, berpendapat bahwa hukumnya makruh, tetapi tetap sah, karena memenuhi syarat dan ketentuan syariat Islam. Sedangkan menurut Syekh Abu Bakar Abdul Aziz dari kalangan Hanabilah nikah sirri yang menyuruh kedua saksi merahasiakannya tidak sah. ${ }^{17}$

Jadi, nikah sirri yang disaksikan dua saksi, namun kedua saksi tersebut disuruh merahasiakannya, penulis lebih condong pendapat ulama Hanafiyah dan Syafiiyah, yang menyatakan sah. Hal ini karena sudah memenuhi syarat dan ketentuan dalam pernikahan. Dan hal ini sudah memenuhi nilai-nilai maqashid syariah dalam pernikahan. Yaitu hifdzu al-nasl, menjaga keturunan dan mencegah dari terjadinya zina.

\section{Penutup}

Menurut mayaritas Ulama dari kalangan Hanafiah, Syafiah dan Hanabilah, nikah sirri adalah pernikahan yang tidak dihadiri dua saksi. Sehingga Pernikahan yang disaksikan dua saksi menurut mereka adalah pernikahan 'alaniyah (bukan pernikahan sirri).

Sedangkan menurut madzhab Ulama Malikiah, terbagi dua pendapat: Pertama; menurut al-Baji, nikah sirri adalah pernikahan yang dirahasiakan kepada halayak umum kecuali kepada dua saksi. Kedua; menurut Ibnu Rif'ah, nikah sirri adalah pernikahan yang diwasiatkan baik kepada saksi ataupun selain saksi, agar pernikahan tersebut dirahasiakan. Dan yang berwasiat untuk merahasiakan adalah suami.

Nikah sirri marak dilakukan dari kalangan rakyat biasa, hingga pejabat tinggi negara. Terkadang nikah sirri juga dipraktikkan oleh kalangan pelajar/mahasiswa. Karena bagi mereka, pernikahan dini

16 Alauddin al-Kasany, Badai' Shona-i', (Beirut: Dar al-Kutub al-Ilmiyah, cet. 2, 1986 M/1406 H), juz 2, 253, Muhammad al-Dasuqi, hasiyah al-Dasuqi, (Beirut: Dar al-Fikr, tc, tt,), juz 2, 236-237, Muhammad al-Mawardi, al-Hawi al-Kabir, (Beirut: Dar al-Kutub al-Ilmiyah, cet. 1, 1999 M/ 1419 H), juz 11, 86

17 Ibnu Qudamah, al-Mughni, (Kairo: Maktaba al-Qahirah, tc. 1968 M/1388 H), juz 6, 538. 
lebih baik dari pada terjerumus ke lembah pergaulan bebas. Biasanya, sang pria sudah lulus sekolah sedangkan sang wanita masih duduk di bangku sekolah. Sehingga mereka melangsungkan pernikahan sirri. Nikah sirri semacam ini sesuai dengan syarat dan ketentuan syariat Islam, bahkan sampai mengundang tetangga untuk resepsi pernikahan, hanya saja tidak dicatat dalam KUA karena sang mempelai wanita masih duduk di bangku sekolah.

Beda halnya nikah sirri di Arab saudi dan Negara Timur Tengah lainnya. Nikah sirri di negara minyak tersebut sangatlah rahasia. Bahkan terkadang hanya diketahui oleh orang-orang tertentu; biasanya wali dan dua saksi.

Inti dari maqashid syariat Islam adalah mewujudkan kemaslahatan dan mencegah mafsadah. Imam al-Ghazali mendifinisikan maslahat dengan menjaga tujuan syariat Islam yang terangkum dalam lima prinsip dasar (baca, Kulliyatu al-Khamsah). Kulliyatu al-Khamasah yaitu hifdzu al-Dien, hifdzu al-Nafs. hifdzu alNasl, hifdzu al-Mal, dan hifdzu al-Aql.

Pernikahan nikah sirri yang tidak disaksikan dua saksi, tidak sah karena tidak memenuhi syarat dan rukun dalam pernikahan, Sedangkan nikah sirri yang disaksikan oleh dua saksi yang keduanya disuruh merahasiakan, maka penulis condong kepada pendapat ulama Hanafiah, Syafiiyah, dan sebagian ulama Malikiyah, pernikahan sirri yang disaksikan dua saksi yang keduanya disuruh merahasiakannya, maka hukumnya sah. Karena hal ini sudah memenuhi nilai-nilai maqashid syariah dalam pernikahan. Yaitu hifdzu al-nasl, menjaga keturunan dan mencegah dari terjadinya zina.

Dalam maqashid syariah pernikahan ada yang bersifat primer (daruriyah) yaitu hifdzu al-nasl yang aplikasinya menjaga keturunan dan mencegah terjadina zina. Kemudian maqashid syariah penikahan yang bersifat sekunder (hajiyah), untuk mewujudkan keluarga yang sakinah, mawaddah wa rahmah. Sedangkan yang bersifat tersier (tahsiniyah) untuk memenuhi kebutuhan psikologis manusia, karena setiap manusia sejatinya hidup berpasangan.

\section{Daftar Rujukan}

Ahmad Al-Hamwy, Al-Mishbah al-Munir, Beirut: al-Maktabah al-Ilmiyah, tc, tt. 
Ahmad ibn Umar al-Syathiri al-Yamany, Yaqut al-Nafis, Demasyqus: Muassasah al-Risalah Nasherun, cet. I, tt..

Alauddin al-Kasany, Badai' Shona-i', Beirut: Dar al-Kutub alIlmiyah, cet. 2, $1986 \mathrm{M} / 1406 \mathrm{H}$.

Al-Bayhaqi, al-Sunan al-Kubra, India: Dairah al-Ma'arif alUstmaniyah, cet. 1, $1344 \mathrm{H}$.

Al-Ghazaly, al-Mustashfa, Beirut: Dar al-Kutub al-Ilmiyah, cet. 1, $1993 \mathrm{M} / 1413 \mathrm{H}$.

Al-Mahally, Syarh al-Jalal Mahally 'ala Jam'i al-Jawami', Beirut: Dar al-Kutub al-Ilmiyah, tt, tc..

Al-Manawi, Faidhu al-Qadir, Mesir: al-Maktabah al-Tijariyah alKubra, cet. 1, $1356 \mathrm{H}$.

M.

Al-Syatiby, al-Muwafaqat, Dar Ibnu Affan, cer. 1, 1997 M/1417

Ibnu Asyur, Maqashid al-Syariah al-Islamiyah, Yordania; Dar alNafais, cet. II, 1421 H/ 2001 M.

Ibnu Qudamah, al-Mughni, Kairo: Maktaba al-Qahirah, tc. 1968 $\mathrm{M} / 1388 \mathrm{H}$.

Imam al-Tirmidzi, Sunan al-Tirmidy, Mesir: al-Halby, cet. II, 1975 M/ $1395 \mathrm{M}$.

Imam Malik, al-Muwaththa', Demasyqus: Dar al-Qalam, cet. I, $1991 \mathrm{M} / 1413 \mathrm{H}$.

Kamus Al-Munawwir aplikasi offline.

Malik al-Madani, al-Mudawwanah, Beirut: Dar al-Kutub alIlmiyah, $1994 \mathrm{M} / 1415 \mathrm{H}$.

Muhammad al-Dasuqi, hasiyah al-Dasuqi, Beirut: Dar al-Fikr, tc, tt.

Muhammad al-Mawardi, al-Hawi al-Kabir, Beirut: Dar al-Kutub al-Ilmiyah, cet. 1, $1999 \mathrm{M} / 1419 \mathrm{H}$.

Syamsuddin al-Ru'ayni, Mawahibu al-Jalil, Beirut: Dar al-Fikr, cet. III, $1992 \mathrm{M} / 1412 \mathrm{H}$. 